\title{
Appropriate Management of Coronary Artery Disease
}

\author{
Mohamed Z. Khalil ${ }^{1 *}$ and Mansour M Al Nozha ${ }^{2}$
}

${ }^{1}$ Consultant Cardiologist, Department of Medicine, Saudi British Hospital, Riyadh, Saudi Arabia

${ }^{2}$ Consultant Cardiologist, Founder of Saudi Heart Association, President (past), Taibah University, Madina, Saudi Arabia

\begin{abstract}
The management of coronary artery disease (CAD) includes three important steps; investigations to establish the disease, and strategies for treatment, and preventive measures. Over the past three decades, the medical community has witnessed a massive number of different modalities for the management of CAD in its three dimensions. These management strategies have been evaluated in a large number of prospective and retrospective trials that eventually resulted in mountain of evidence which probably created more confusion rather than simplicity for the treating physician. As a result, several guidelines were recommended based on available evidence; nonetheless, the decisions for CAD management in clinical practice do not necessarily follow these guidelines worldwide. Therefore, the objective of this article is to methodically simplify the management of CAD in light of recent published evidence.
\end{abstract}

Keywords: Coronary artery disease; Diagnosis; Management; Angina; Myocardial Infarction

\section{Development of CAD}

It takes long duration after exposure to the well known risk factors for $\mathrm{CAD}$ prior to its development, giving a chance for prevention [13]. The definition of CAD is a coronary artery that is abnormal in its function owing to narrowing or obstruction of its lumen leading to reduction of blood flow with subsequent less blood supply to designated portion of the cardiac muscle.

From basic understanding of simple physics and hemodynamics, we know that flow in a vessel is directly related to pressure as well as the diameter of the vessel and inversely related to resistance [4-6]. Consequently, the reduction in blood flow in patients with CAD is a result of reduced diameter, increase resistance or relative reduction of pressure needed for the flow. Factors working on the coronary artery endothelium are well understood to be mediated by inflammatory process and in the vast majority of patients with CAD; the process is rather diffuse affecting longer segments of the diseased coronary artery [7-9].

\section{Diagnosis of CAD}

\section{History of chest pain}

Evaluating patients with history of chest pain as a manifestation of CAD remains challenging, regardless of many insights and innovations over the past three decades. Obviously, CAD's chest pain is a product of reduced perfusion (ischemia) of a certain myocardial segment as a result of less blood supply facing a demand of the same segment. Therefore, the typical ischemic chest pain can easily be defined as an exertional chest pain, relieved by cardiac rest, and has the characteristics of angina.

Furthermore, relief of chest pain after nitroglycerin treatment does not predict active CAD, as it was found nonspecific for angina pectoris [10]. Ischemic pain is generally described by patients vaguely as a discomfort rather than pain nonetheless; it is usually not felt as stabbing, or sharp pain. It is gradual in onset, however, its intensity may wax and wane, it radiates to other parts of the body characteristically to the upper extremities. The duration of the pain is typically used to classify either angina pectoris if it lasts less than twenty to thirty minutes, while the duration that lasts longer than 30 minutes is seen in patients with an acute coronary syndrome (ACS).
Ironically, despite a chest pain that feared to be a manifestation of $\mathrm{CAD}$, further investigations may point out towards another diagnosis, as in the vast majority of patients with chest pain, CAD may be entirely asymptomatic or presenting in symptoms other than chest pain. Silent ischemia secondary to CAD has been reported to occur in up to $75 \%$ of all patients; however, certain registries have reported lack of chest pain in one third of patients diagnosed as having myocardial infarction (MI), presenting with other symptoms such as breathlessness, palpitations, nausea, vomiting, or syncope [11].

The chest pain as a sole presenting symptom of CAD is no diagnostic value since it has not proven to be a powerful predictive tool to obviate the need for at least some diagnostic testing [12].

\section{Electrocardiogram (ECG)}

A resting 12 lead ECG is the first investigation in the assessment of any patient presenting with symptoms suggestive of CAD. It is a noninvasive, readily available, easy to interpret, and it can provide valuable information in a very short time. Nonetheless, it may overlook CAD, particularly, when it is performed during a resting myocardium.

Stress ECG, however, may be performed in patients presenting with chest pain that proved to be outside the spectrum of acute coronary syndrome (ST or non ST segment elevation MI, or unstable angina) with variable sensitivity and specificity. The exercise ECG cannot be interpreted in the presence of resting ST segment changes (more than $1 \mathrm{~mm}$ ST depression at rest), left ventricular hypertrophy (LVH), left bundle branch block (LBBB), a ventricular paced rhythm, or the Wolff Parkinson White (WPW) syndrome.

Several investigators looked at the accuracy of establishing a solid

*Corresponding author: Dr. Mohamed Z. Khalil, Consultant Cardiologist, Saudi British Hospital P. O. Box 285627, Riyadh, Saudi Arabia, Tel: 966 550055587; Fax: 966 12012532; E-mail: mzkhalil@hotmail.com

Received November 07, 2012; Accepted November 23, 2012; Published November 26, 2012

Citation: Khalil MZ, Al Nozha MM (2012) Appropriate Management of Coronary Artery Disease. Adv Pharmacoepidem Drug Safety 1:122. doi:10.4172/21671052.1000122

Copyright: @ 2012 Khalil MZ, et al. This is an open-access article distributed under the terms of the Creative Commons Attribution License, which permits unrestricted use, distribution, and reproduction in any medium, provided the original author and source are credited. 
result of CAD based on stress ECG among different sets of patients with an agreement for a positive result. The meta-analysis of the results in patients with an intermediate pretest risk of CAD revealed an overall $68 \%$ sensitivity and $77 \%$ specificity [13]. Accordingly, nearly one third of patients with CAD are missed and one fourth has shown false positive results. It is important to emphasize that an ischemic myocardium may generate changes in the electricity detected by an ECG recording. Hence an abnormal ECG is an indirect way of evaluating reduced blood flow through the coronary vessels secondary to tight lumen either due to an obstructive lesion, non-obstructive lesion, or vessel spasm. Consequently, if the test is positive in a patient with multiple risk factors of $\mathrm{CAD}$ and typical anginal chest pain; a diagnosis of CAD may be established, however, in that same given patient, a negative test should not exclude the disease and further evaluation is categorically indispensable.

Therefore, exercise ECG is a tool that can be used in patients who are able to achieve an adequate workload (defined as $85 \%$ of their agepredicted maximum heart rate) with an intermediate or high pretest probability for $\mathrm{CAD}$, but without abnormalities that can interfere with interpretation of the ECG.

\section{Cardiac biomarkers}

CAD has a wide spectrum of manifestations based on the extent of blood flow reduction; starting with asymptomatic CAD passing through stable angina, and ending with a catastrophic MI secondary to complete cessation of blood supply leading to cardiac cell death. The biochemical characteristics of myocardial necrosis are troponins, and the myocardial band of creatine kinase (CK-MB). Troponins may be detected as early as two hours post cardiac injury and last for duration of up to 10 days. CK-MB level, on the other hand, rises post cardiac injury in four hours and disappears in 48 hours. Reversible ischemia to the myocardium has not been shown to elevate troponins; signifying release of these markers is specific to cardiac cell death (necrosis) and not ischemia [14].

There are two forms of cardiac troponins: I (cTnI) and T (cTnT) both are considered specific to cardiac necrosis, however, early studies have demonstrated that cTnI is found only in sera of patients with myocardial injury in comparison to cTnT that is released in undetectable quantities by first generation assays from skeletal muscle [15-17].

The lack of standardization of different assays in the biochemistry laboratory caused marked clinical confusion in interpreting the result of troponins. In the absence of any minor degree of myocardial injury, the troponins assay should be undetectable [18]. Nonetheless, this particular matter is not true in clinical practice, as often the case with patients who present with chest pain and positive troponins, while further evaluation reveals lack of myocardial injury after wasting considerable efforts and resources. To solve this problem; it has been recommended that each biochemistry laboratory should define its cutoffs for each test at the 99th percentile of a normal reference population, and this cutoff value should be measurable with a coefficient of variation $(\mathrm{CV})$ of $10 \%$ or less [19].

Cardiac troponins represent an important tool to the clinician in the diagnosis as well as risk stratification and prognosis of patients with ACS as a result of CAD with the limitation of a chemistry laboratory's reliability. Additionally, cardiac injury is not exclusively caused by occlusion of blood supply secondary to CAD, as many other reasons are known to cause myocardial damage.

\section{Myocardial perfusion imaging (MPI)}

MPI is an attractive method in evaluating the extent of reduced perfusion, viability, and the functional capacity of the myocardium in a patient with CAD particularly, when comparing stress to rest images. However, MPI is unreliable in patients with LBBB, a paced ventricular rhythm, patients who are taking digoxin or have LVH due to transient positive defects in the anteroseptal and septal regions in the absence of CAD reducing the sensitivity of MPI.

Interpretation of MPI may cause uncertainty in the presence of CAD decreasing test specificity, attributed to image attenuation artifacts derived from breast tissue, and diaphragmatic attenuation in obese patients. Newer isotope agents have higher photon energy and shorter half-life resulting in improved image quality. Moreover, ECG gated single-photon emission computed tomography (gated SPECT) acquisition, permitting the simultaneous evaluation of left ventricular systolic function, myocardial perfusion and the identification of attenuation artifacts, in the absence of myocardial stunning, has been shown to improve test specificity [20-22].

Many factors can affect the sensitivity and specificity of perfusion imaging in identifying CAD such as the location, extent, and degree of coronary artery stenosis, as well as the pretest clinical likelihood of CAD. The overall sensitivity of MPI for detecting CAD is in the vicinity of $90 \%$; ranging from $83 \%$ for the detection of single vessel disease to $93 \%$ for double vessel disease to $95 \%$ for triple vessel disease, while the overall specificity of MPI is in the region of 70\% [23].

More recent trials have established the role of MPI as a noninvasive modality for risk stratification of CAD, and suitable step in guiding treatment strategy by either optimal medical therapy (OMT) or invasive coronary intervention. The dual-isotope imaging approach showed higher sensitivity and specificity for CAD, however, single-isotope imaging has several advantages, over dual-isotope imaging; including flexibility of performing the test as well as easier image interpretation, making single isotope imaging is the MPI modality of choice [24-26].

MPI has been effectively utilized as a prognostic tool as evidenced in one large trial (10,627 patients) by survival benefit in patients with moderate to large amounts of inducible ischemia who underwent revascularization compared to medical therapy alone, particularly in higher risk patients [27].

MPI is a useful tool for the assessment of selected patients in reaching the diagnosis as well as the prognosis of CAD; however, MPI should not be used as the initial test for CAD risk stratification in patients who have no contraindications to exercise ECG test.

\section{Computed tomography angiography (CTA)}

Coronary artery anatomy may be assessed by non-invasive imaging such as CTA or magnetic resonance imaging (MRI); however, the constant motion of the beating heart lashed out, at present, MRI as a tool of evaluating CAD structurally, despite several attempts to overcome this obstacle by developing specific software for detecting CAD by MRI, nonetheless, it may become an important diagnostic tool in the near future $[28,29]$. Meanwhile, CTA has been progressively developed and widely used as a diagnostic tool for patients suspected of having CAD.

Electron beam computed tomography (EBCT) has inferior image quality compared to multi-slice computed tomography (MSCT), otherwise known as multi-detector row computed tomography (MDCT) that has higher spatial but lower temporal resolution than EBCT with much higher radiation doses. 
MDCT after intravenous contrast agent administration enables visualization of the coronary arteries with high temporal and spatial resolution allowing imaging of the beating heart without motion artifact, particularly after the administration of heart rate reducing agent (beta blocker) and vasodilating agent (nitroglycerin). The overall sensitivity for MDCT in detecting CAD has been ranging from $80 \%$ to $94 \%$ depending on the degree, extent, and location of stenosis, while the overall specificity may reach up to $97 \%$, with positive predictive value around $87 \%$, and negative predictive value of $99 \%$ allowing it to be a powerful tool in excluding CAD in patients with low pretest probability of having CAD [30-42].

Clinically, selecting patients to undergo MDCT remains an important step in determining the result of the test in ruling out the presence of CAD. The optimal patient to facilitate scanning and improve image quality is one who can sustain a breath hold for at least 15 to 20 seconds, with regular heart rate of less than 60 beats/ minute; as faster or irregular heart rates (such as atrial fibrillation or frequent premature beats) may interfere with the diagnostic quality of images. Consequently, MDCT is the modality of choice in excluding CAD while evaluating patients pre-operatively for cardiac valve replacement. Clearly, the hazards of high doses of radiation exposure during acquisition of MDCT have to be considered against the benefits of having the test $[43,44]$.

Apparently, for the reason that radiation exposure carries a considerable risk for future medical disorders; MDCT may not be used as screening tool for healthy individuals. Furthermore, the presence of calcified coronary vessels in elderly patients may interfere with proper interpretation of MDCT.

\section{Echocardiography}

Echocardiography is the most widely used imaging method in cardiology. It provides excellent information on morphology and function of nearly all cardiac structures. In-contrast to other cardiac non-invasive imaging, echocardiography is performed by, or under the supervision of, cardiologists making acquisition and interpretation of images in the hands of the managing physician. Resting trans-thoracic echocardiography (TTE) may assess the structure and function of different segments of the cardiac muscle as well as demonstrating intra-ventricular abnormalities such as a thrombus. Moreover, its superiority, particularly trans-esophageal echocardiography (TEE), has been revealed in evaluating patients with suspected proximal aortic dissection that may present in similar clinical scenario as ACS. Probably, in the coming future with advances made in the technology of image acquisition, direct evaluation of coronary vessels may be feasible in the same fashion as large vessels are being evaluated currently.

Stress echocardiography has been proven to be a reliable tool for the demonstration of myocardial ischemia by showing inducible wall motion abnormalities that indirectly reflect reduced blood supply through a diseased coronary artery, as well as the assessment of viable myocardium. Among different stressors of the heart, dobutamine stress echocardiography (DSE) has been increasingly used as the preferred stress method compared to exercise or other pharmacological agents. Obviously, DSE is contraindicated in the setting of ACS, severe left ventricular outflow obstruction, severe aortic stenosis, or aortic dissection. Furthermore, the presence of LBBB or paced rhythm interferes with proper assessment of left ventricular wall motion abnormalities due to CAD by DSE hence its efficacy is not well established in this group of patients.

Technically, DSE is performed by the administration of intravenous dobutamine in graded three minute doses, starting with a dose of $5 \mu \mathrm{g} /$ $\mathrm{kg} / \mathrm{min}$, reaching a peak maximum dose of $40 \mu \mathrm{g} / \mathrm{kg} / \mathrm{min}$. Atropine can be added if $85 \%$ of maximum predicted target heart rate for age is not achieved at the peak dose of dobutamine. Acquisitions of echocardiographic imaging of the same cardiac segments are obtained during the final minute of each stage. The overall sensitivity of DSE was found to be around $80 \%$, while the specificity was approximately $84 \%$ based on the extent of CAD stenosis, the amount of myocardium supplied by diseased coronaries, and the degree of quantitative or qualitative deterioration in left ventricular wall motion [45-49]. Moreover, the use of contrast echocardiography has been shown to improve the sensitivity of DSE for detecting CAD [50].

DSE is the stress test of choice in patients with LVH, particularly when ECG abnormalities of more than $1 \mathrm{~mm}$ ST segment depression preclude exercise ECG, and DSE has been shown to be more sensitive than MPI in detecting CAD in this set of patients [51].

\section{Coronary Angiography (CAG)}

The gold standard test in evaluating CAD remains to be coronary angiography (CAG); as it provides visualization of the vascular lumen. In some instances, however, the visualization of coronary vessels is not complete, and in most of the cases is due to total occlusion of the vessel.

Besides, CAG can miss CAD in patients with diffuse plaque that is uniformly distributed all over coronary vessel without focal infringement on the lumen, particularly in relatively small vessel (lumen diameter $<2 \mathrm{~mm}$ ) with compensatory enlargement. In such a case, an intravascular ultrasound (IVUS) study will be able to visualize that kind of lesion [52].

In addition, false positive coronary stenosis may be seen on CAG images in normal coronary vessel due to spasm that can be easily normalized by the use of vasodilators, and reproduced by challenge test.

CAG is an invasive test that carries considerable concerns for morbidity and in rare incidences mortality making one think twice before proceeding with CAG either for diagnosis of CAD or as treatment. Complications of CAG may be as a consequence of access site resulting in hematomas, arterio-venous fistulas, pseudo-aneurysm, arterial thrombosis, and infection.

Complications may arise from advancement of the catheter leading to embolic events, stroke, transient ischemic attack (TIA), myocardial infarction (MI), arrhythmias, and perforation of the heart or great vessels. Other complications of CAG may be related to radio-contrast agent resulting in hypersensitivity reactions, anaphylactic shock, or contrast nephropathy leading to acute renal failure (ARF). Radiation exposure during CAG carries considerable risk to both patient and staff.

As outlined above, CAG cannot be used routinely in evaluating patients with suspected CAD; hence patients should be selected carefully prior to performing CAG. Moreover, knowing the anatomy of coronary vessels as well as the extent of CAD is only helpful in a certain group of patients but not all those with CAD.

\section{Treatment of CAD}

\section{Optimal medical therapy (OMT)}

The wide range of clinical scenarios as a result of CAD can be simplified by treating patients into two main categories; unstable patients presenting as acute coronary syndrome (ACS) or stable patients presenting as chronic angina. 
Patients with chronic stable angina can be safely treated with medical therapy without percutanous coronary intervention (PCI), provided that their medical therapy is optimal defined as intensive medical therapy, a reduction of risk factors, as well as lifestyle modification, additionally, they should be motivated with evidence of compliance by reaching the desired targets in their follow up visits. This concept has been demonstrated in the "COURAGE" trial comparing OMT to PCI plus OMT in patients with stable angina; the authors concluded in clear and robust statement: "as an initial management strategy in patients with stable CAD, PCI did not reduce the risk of death, MI, or other major cardiovascular events when added to OMT" [53].

Furthermore, the quality of life (QoL) in patients with stable CAD treated with OMT was evaluated by QoL analysis and was shown that OMT without routine PCI rapidly improved the patients' Seattle Angina Questionnaire (SAQ) scores for physical limitation, angina frequency, and overall QoL [54].

Recommendations have been clear in several guidelines to start with OMT in patients with stable CAD, however, clinical practice has gone out of line in centers with facility for PCI utilizing invasive strategy over OMT due to the pressure and fear of medico-legal litigation that has been cleared by unequivocal evidence to support OMT as an initial treatment. Nonetheless, PCI remains an option for patients with persistent symptoms despite OMT, provided that treatment targets have been achieved in terms of lifestyle intervention as well as lipids and other CAD risk factors [55].

It is essential to point out that OMT remains a powerful tool in the treatment toolbox for patients with CAD. OMT should include an antiplatelet therapy, beta blocker agent, calcium channel blocker agent, angiotensen converting enzyme (ACE) inhibitor, or angiotensen receptor blocker (ARB), isosorbide mononitrate, alone or in combination according to the clinical variables of each patient. Additionally, patients have to permit aggressive therapy to lower lowdensity lipoprotein (LDL) cholesterol to a target level of $70 \mathrm{mg} /$ deciliter (1.8 mmol/liter), stop smoking, and exercise on daily basis. Above all, patients should be assured that OMT is mandatory for secondary prevention of CAD, and the addition of PCI to OMT did not create any significant difference neither in mortality nor prevention of MI.

\section{Percutanous coronary intervention (PCI)}

As outlined above, there is no evidence that PCI has survival benefit or prevent $\mathrm{MI}$ in patients with non-acute coronary artery syndrome compared with medical therapy. Chronic stable CAD is a diffuse disease process, making it more likely to respond to systemic treatment such as medical therapy compared to local therapy using PCI. On the other hand, PCI has definite survival benefit over medical therapy in patients with ACS or those who present with cardiogenic shock when performed by skilled operators in timely approach.

Early intervention relied mainly on balloon dilation (angioplasty), however, due to failure rate to maintain target vessel lesion patent, and to reduce target vessel revascularization (TVR); the use of stent was introduced to overcome such problem [56-60].

The different types of stents as well as technical aspects of the procedure of PCI are beyond the scope of this article. Nonetheless, early referral to a cardiac center with PCI facility is a definite necessity in patients with CAD presenting with ACS. The referral has to be as early as possible for maximum myocardial salvage. However, one should always weigh the risk of referral to the benefit of PCI, particularly; other medical therapy such as fibrinolytic (thrombolytic) agents or glycoprotein IIB/IIIA inhibitors and other therapeutic agents are readily available in most centers without PCI facility.

\section{Surgical coronary revascularization}

Coronary artery bypass grafting $(\mathrm{CABG})$ has been the procedure of revascularization of choice prior to the introduction of PCI. Improvements in CABG since its introduction in 1968 included offpump CABG, smaller incisions, enhanced myocardial preservation, use of arterial conduits instead of venous grafts, and better postoperative care have reduced mortality, morbidity, and rates of graft occlusion [61$66]$.

Meta analyses of several trials comparing CABG versus PCI in patients with multivessel $\mathrm{CAD}$ has documented insignificant superiority of CABG regarding survival, however, definite reduction in TVR with no verdict on which procedure should be the standard of care in treating such patient [67].

More recently, clear evidence shows that in patients with more severe CAD, and especially those with diabetes as well as patients of 65 years or older, $C A B G$ is superior in terms of survival and freedom from future intervention $[68,69]$.

It remains a major concern about the availability of skilled cardiac surgeons as well as cardiac interventionists in order to provide the standard revascularization of care presented in the medical literature. Moreover, there are many limitations in clinical trials to draw concrete conclusions such as short duration of follow ups as well as drop out of treated patients in the final analysis that may give rise to false impression; hence medical care is ever changing.

Nonetheless, at present time we should adopt the evidence presented to us that CABG, as compared with PCI, is associated with a lower rate of major adverse cardiac or cerebrovascular events among patients with three-vessel CAD, diabetics with multi-vessel disease, left main disease as well as elderly patients with CAD and should therefore remain the standard of care for such patients.

\section{Prevention of CAD}

It is ironic that with the rapid economic development people turn to lead easy and sedentary lifestyle, the price of which is paid in terms of diseased human bodies as a result of CAD. Al-Nozha et al. explored the prevalence of CAD its risk factors in a community based national study that has revealed an increase in the prevalence of CAD and its risk factors in Saudi Arabia: an example of a population with a rapid change towards sedentary lifestyle [70-75]. Clearly, obesity and its corollary medical disorders: such as hypertension, the metabolic syndrome, and diabetes mellitus are the main risk factors for CAD. They are principally due to easy lifestyle with less exercise and more tasty but unhealthy food intake. Sedentary lifestyles are not the only cause of CAD otherwise patients with active life should not develop CAD. Nonetheless, current evidence supports the reversal of the development of CAD and its risk factors by adopting preventive measures the whole mark of which is less eating and more exercise [76-80].

Moreover, it is important to emphasize that prevention should focus on younger healthy children primarily to prevent the development of CAD (primary prevention) and its risk factors [81-86]. However, there is still beneficial outcome from secondary prevention in controlling the progression of CAD and its risk factors [87-95].

Vascular inflammation plays a pivotal role in the development of atherosclerosis and CAD. Inflammation may affect the endothelium 
of the epicardial coronaries in a diffuse pattern or more commonly involves certain parts of the vessels producing focal lesions. It has been shown by several epidemionological studies that exposure to risk factors that are known to increase the risk of developing CAD can be altered by modifying the reversible risk factors as preventive measures to CAD [96-97].

Prevention may be enforced through community health education to implement individual responsibilities at early age to avoid obesity, cigarette smoking, keeping normoglycemic and normotensive states at all times as well as maintaining an LDL level in the desirable range according to the presence or absence of CAD risk factors.

Physical inactivity is a well-established risk factor for CAD and is associated with a twofold increase in the development of CAD [98]. It is not just obesity that causes the increase of risk for CAD in physically inactive individuals, as we understand that caloric expenditure by excessive physical activity does not exceed by any means the basal metabolic rate in physically inactive individuals. It is basically visceral obesity and waist hip ratio that is likely to be affected by physical activity in addition to other factors probably related to reduction in the components of the metabolic syndrome.

MI is the catastrophic event on the scale of CAD and it is clear that the activation of unstable plaque precipitates the infarction by formation of an occluding thrombus on the surface of the ruptured plaque [99]. Hence, aggressive medical therapy aiming at reversal of the plaque should be our target in achieving secondary prevention of CAD.

\section{Summary}

As risk factors for CAD are on the rise due to current sedentary lifestyle that matches transformation towards industrialization throughout the world; the prevalence of CAD is obviously has to increase. Moreover, our understanding of various presentations of $\mathrm{CAD}$, along with the continuous improvement in diagnostics, may have been the main reason behind variability in the management of CAD; both diagnosis as well as treatment.

Angina or typical ischemic chest pain as a presentation of CAD needs simple evaluation at first to determine whether it is acute or chronic, and if acute is it stable or unstable. Easily, the answer can be made using EKG and cardiac biomarkers when appropriate. For patients with ACS and elevated cardiac biomarkers; treatments have to be instituted on an emergency basis, with an aim for revascularization. While patients without elevated cardiac biomarkers during the initial 12 hours of assessment, may require further form of stress testing to confirm the presence of CAD and initiate OMT.

Diabetic patients with multi vessel CAD as well as those with triple vessel disease should choose CABG as the revascularization option of choice according to the expertise of the available cardiac surgery center as compared to PCI. OMT remains an important step in the management of patients with CAD irrespective of the choice of revascularization chosen. Nonetheless, prevention of CAD remains to be major health issue.

\section{References}

1. Zeymer U, Parhofer KG, Pittrow D, Binz C, Schwertfeger M, et al. (2009) Risk factor profile, management and prognosis of patients with peripheral arterial disease with or without coronary artery disease: results of the prospective German REACH registry cohort. Clin Res Cardiol 98: 249-256.

2. Remme WJ, Deckers JW, Fox KM, Ferrari R, Bertrand M, et al. (2009) Secondary prevention of coronary disease with ACE inhibition-does blood pressure reduction with perindopril explain the benefits in EUROPA? Cardiovasc Drugs Ther 23: 161-170.

3. Voller H, Reibis R, Pittrow D, Jannowitz C, Wegscheider K, et al. (2009) Secondary prevention of diabetic patients with coronary artery disease in cardiac rehabilitation: risk factors, treatment and target level attainment. Curr Med Res Opin 25: 879-890.

4. Spaan JA, Piek JJ, Hoffman JI, Siebes M (2006) Physiological basis of clinically used coronary hemodynamic indices. Circulation 113: 446-455.

5. Hoffman JI, Spaan JA (1990) Pressure-flow relations in coronary circulation Physiol Rev 70: 331-390.

6. Duncker DJ, Bache RJ (2008) Regulation of coronary blood flow during exercise. Physiol Rev 88: 1009-1086.

7. Libby P, Theroux P (2005) Pathophysiology of coronary artery disease Circulation 111: 3481-3488

8. Spagnoli LG, Bonanno E, Mauriello A, Palmieri G, Partenzi A, et al. (2002) Multicentric inflammation in epicardial coronary arteries of patients dying of acute myocardial infarction. J Am Coll Cardiol 40: 1579-1588.

9. Mauriello A, Sangiorgi G, Fratoni S, Palmieri G, Bonanno E, et al. (2005) Diffuse and active inflammation occurs in both vulnerable and stable plaques of the entire coronary tree: a histopathologic study of patients dying of acute myocardial infarction. J Am Coll Cardiol 45: 1585-1593.

10. Henrikson CA, Howell EE, Bush DE, Miles JS, Meininger GR, et al. (2003) Chest pain relief by nitroglycerin does not predict active coronary artery disease. Ann Intern Med 139: 979-986.

11. Canto JG, Shlipak MG, Rogers WJ, Malmgren JA, Frederick PD, et al (2000) Prevalence, clinical characteristics, and mortality among patients with myocardial infarction presenting without chest pain. JAMA 283: 3223-3229.

12. Swap CJ, Nagurney JT (2005) Value and limitations of chest pain history in the evaluation of patients with suspected acute coronary syndromes. JAMA 294: 2623-2629.

13. Gianrossi R, Detrano R, Mulvihill D, Lehmann K, Dubach P, et al. (1989) Exercise-induced ST depression in the diagnosis of coronary artery disease. A meta-analysis. Circulation 80: 87-98.

14. Carlson RJ, Navone A, McConnell JP, Burritt M, Castle MC, et al. (2002) Effect of myocardial ischemia on cardiac troponin I and T. Am J Cardiol 89: 224-226.

15. Bodor GS, Porterfield D, Voss EM, Smith S, Apple FS (1995) Cardiac troponin-I is not expressed in fetal and healthy or diseased adult human skeletal muscle tissue. Clin Chem 41: 1710-1715.

16. Ricchiuti V, Voss EM, Ney A, Odland M, Anderson PA (1998) Cardiac troponin $T$ isoforms expressed in renal disease skeletal muscle will not cause falsepositive results by the second generation cardiac troponin $\mathrm{T}$ assay by Boehringer Mannheim. Clin Chem 44: 1919-1924.

17. Adams JE 3rd, Bodor GS, Dávila-Román VG, Delmez JA, Apple FS, et al (1993) Cardiac troponin I. A marker with high specificity for cardiac injury. Circulation 88: 101-106.

18. Wallace TW, Abdullah SM, Drazner MH, Das SR, Khera A, et al. (2006) Prevalence and determinants of troponin T elevation in the general population. Circulation 113: 1958-1965.

19. Alpert JS, Thygesen K, Antman E, Bassand JP (2000) Myocardial infarction redefined-a consensus document of The Joint European Society of Cardiology/ American College of Cardiology Committee for the redefinition of myocardia infarction. J Am Coll Cardiol 36: 959-969.

20. Bavelaar-Croon CD, Pauwels EK, van der Wall EE (2001) Gated single-photon emission computed tomographic myocardial imaging: a new tool in clinical cardiology. Am Heart J 141: 383-390.

21. DePuey EG, Rozanski A (1995) Using gated technetium-99m-sestamibi SPECT to characterize fixed myocardial defects as infarct or artifact. J Nucl Med 36: 952-955.

22. Johnson LL, Verdesca SA, Aude WY, Xavier RC, Nott LT, et al. (1997) Postischemic stunning can affect left ventricular ejection fraction and regional wall motion on post-stress gated sestamibi tomograms. J Am Coll Cardiol 30: 1641-1648.

23. Mahmarian JJ, Verani MS (1991) Exercise thallium-201 perfusion scintigraphy in the assessment of coronary artery disease. Am J Cardiol 67: 2D-11D. 
24. Druz RS (2009) Current advances in vasodilator pharmacological stress perfusion imaging. Semin Nucl Med 39: 204-209.

25. Berman DS, Kiat H, Friedman JD, Wang FP, van Train K, et al. (1993) Separate acquisition rest thallium-201/stress technetium-99m sestamibi dual-isotope myocardial perfusion single-photon emission computed tomography: a clinical validation study. J Am Coll Cardiol 22: 1455-1464.

26. Hachamovitch R, Berman DS, Shaw LJ, Kiat H, Cohen I, et al. (1998) Incremental prognostic value of myocardial perfusion single photon emission computed tomography for the prediction of cardiac death: differential stratification for risk of cardiac death and myocardial infarction. Circulation 97: 535-543.

27. Poornima IG, Miller TD, Christian TF, Hodge DO, Bailey KR, et al. (2004) Utility of myocardial perfusion imaging in patients with low-risk treadmill scores. J Am Coll Cardiol 43: 194-199.

28. Hachamovitch R, Hayes SW, Friedman JD, Cohen I, Berman DS (2003) Comparison of the short-term survival benefit associated with revascularization compared with medical therapy in patients with no prior coronary artery disease undergoing stress myocardial perfusion single photon emission computed tomography. Circulation 107: 2900-2907.

29. Hudsmith LE, Neubauer S (2009) Magnetic resonance spectroscopy in myocardial disease. JACC Cardiovasc Imaging 2: 87-96.

30. Kwong RY (2009) Can cardiac magnetic resonance myocardial scar features affect treatment decisions for patients with coronary artery disease and heart failure? JACC Cardiovasc Imaging 2: 45-47.

31. Budoff MJ, Dowe D, Jollis JG, Gitter M, Sutherland J, et al. (2008) Diagnostic performance of 64-multidetector row coronary computed tomographic angiography for evaluation of coronary artery stenosis in individuals without known coronary artery disease: results from the prospective multicenter ACCURACY (Assessment by Coronary Computed Tomographic Angiography of Individuals Undergoing Invasive Coronary Angiography) trial. J Am Coll Cardiol 52: 1724-1732.

32. Leschka S, Alkadhi H, Plass A, Desbiolles L, Grünenfelder J, et al. (2005) Accuracy of MSCT coronary angiography with 64-slice technology: first experience. Eur Heart J 26: 1482-1487.

33. Gaemperli O, Schepis T, Valenta I, Koepfli P, Husmann L, et al. (2008) Functionally relevant coronary artery disease: comparison of 64-section CT angiography with myocardial perfusion SPECT. Radiology 248: 414-423.

34. Türkvatan A, Biyikoğlu SF, Büyükbayraktar F, Olçer T, Cumhur T, et al. (2008) Clinical value of 16-slice multidetector computed tomography in symptomatic patients with suspected coronary artery disease. Acta Radiol 49: 400-408.

35. Mowatt G, Cummins E, Waugh N, Walker S, Cook J, et al. (2008) Systematic review of the clinical effectiveness and cost-effectiveness of 64-slice or higher computed tomography angiography as an alternative to invasive coronary angiography in the investigation of coronary artery disease. Health Technol Assess 12: iii-iv, ix-143.

36. Leber AW, Knez A, von Ziegler F, Becker A, Nikolaou K, et al. (2005) Quantification of obstructive and nonobstructive coronary lesions by 64-slice computed tomography: a comparative study with quantitative coronary angiography and intravascular ultrasound. J Am Coll Cardiol 46: 147-154.

37. Leber AW, von Ziegler F, Becker A, Becker CR, Reiser M, et al. (2008) Characteristics of coronary plaques before angiographic progression determined by Multi-Slice CT. Int J Cardiovasc Imaging 24: 423-428.

38. Raff GL, Gallagher MJ, O'Neill WW, Goldstein JA (2005) Diagnostic accuracy of noninvasive coronary angiography using 64-slice spiral computed tomography. J Am Coll Cardiol 46: 552-557.

39. Chun EJ, Lee W, Choi YH, Koo BK, Choi SI, et al. (2008) Effects of nitroglycerin on the diagnostic accuracy of electrocardiogram-gated coronary computed tomography angiography. J Comput Assist Tomogr 32: 86-92.

40. Ropers U, Ropers D, Pflederer T, Anders K, Kuettner A, et al. (2007) Influence of heart rate on the diagnostic accuracy of dual-source computed tomography coronary angiography. J Am Coll Cardiol 50: 2393-2398.

41. Hausleiter J, Meyer T, Hadamitzky M, Zankl M, Gerein P, et al. (2007) Noninvasive coronary computed tomographic angiography for patients with suspected coronary artery disease: the Coronary Angiography by Computed Tomography with the Use of a Submillimeter resolution (CACTUS) trial. Eur Heart J 28: 3034-3041.

42. Bordeleau E, Lamonde A, Prenovault J, Belblidia A, Coté G, et al. (2007)
Accuracy and rate of coronary artery segment visualization with CT angiography for the non-invasive detection of coronary artery stenoses. Int $\mathrm{J}$ Cardiovasc Imaging 23: 771-780.

43. Mollet NR, Cademartiri F, van Mieghem CA, Runza G, McFadden EP, et al. (2005) High-resolution spiral computed tomography coronary angiography in patients referred for diagnostic conventional coronary angiography. Circulation 112: 2318-2323.

44. Gerber TC, Stratmann BP, Kuzo RS, Kantor B, Morin RL (2005) Effect of acquisition technique on radiation dose and image quality in multidetector row computed tomography coronary angiography with submillimeter collimation. Invest Radiol 40: 556-563.

45. Morin RL, Gerber TC, McCollough CH (2003) Radiation dose in computed tomography of the heart. Circulation 107: 917-922.

46. Hunold P, Vogt FM, Schmermund A, Debatin JF, Kerkhoff G, et al. (2003) Radiation exposure during cardiac CT: effective doses at multi-detector row CT and electron-beam CT. Radiology 226: 145-152.

47. Kim C, Kwok YS, Heagerty P, Redberg R (2001) Pharmacologic stress testing for coronary disease diagnosis: A meta-analysis. Am Heart J 142: 934-944.

48. Rallidis L, Cokkinos P, Tousoulis D, Nihoyannopoulos P (1997) Comparison of dobutamine and treadmill exercise echocardiography in inducing ischemia in patients with coronary artery disease. J Am Coll Cardiol 30: 1660-1668.

49. Geleijnse ML, Fioretti PM, Roelandt JR (1997) Methodology, feasibility, safety and diagnostic accuracy of dobutamine stress echocardiography. J Am Coll Cardiol 30: 595-606.

50. Garber AM, Solomon NA (1999) Cost-effectiveness of alternative test strategies for the diagnosis of coronary artery disease. Ann Intern Med 130: 719-728.

51. Bartunek J, Marwick TH, Rodrigues AC, Vincent M, Van Schuerbeeck E, et al. (1996) Dobutamine-induced wall motion abnormalities: correlations with myocardial fractional flow reserve and quantitative coronary angiography. J Am Coll Cardiol 27: 1429-1436.

52. Tsutsui JM, Elhendy A, Anderson JR, Xie F, McGrain AC, et al. (2005) Prognostic value of dobutamine stress myocardial contrast perfusion echocardiography. Circulation 112:1444-1450

53. Marwick T, D'Hondt AM, Baudhuin T, Willemart B, Wijns W, et al. (1993) Optimal use of dobutamine stress for the detection and evaluation of coronary artery disease: combination with echocardiography or scintigraphy, or both? J Am Coll Cardiol 22: 159-167.

54. von Birgelen C, Mintz GS, de Vrey EA, Kimura T, Popma JJ, et al. (1998) Atherosclerotic coronary lesions with inadequate compensatory enlargement have smaller plaque and vessel volumes: observations with three dimensional intravascular ultrasound in vivo. Heart 79: 137-142.

55. Boden WE, O'Rourke RA, Teo KK, Hartigan PM, Maron DJ, et al. (2007) Optimal medical therapy with or without $\mathrm{PCl}$ for stable coronary disease. N Engl J Med 356: 1503-1516.

56. Shaw LJ, Berman DS, Maron DJ, Mancini GB, Hayes SW, et al. (2008) Optimal medical therapy with or without percutaneous coronary intervention to reduce ischemic burden: results from the Clinical Outcomes Utilizing Revascularization and Aggressive Drug Evaluation (COURAGE) trial nuclear substudy. Circulation 117: 1283-1291.

57. Peterson ED, Rumsfeld JS (2008) Finding the courage to reconsider medical therapy for stable angina. N Engl J Med 359: 751-753.

58. Serruys PW, de Jaegere P, Kiemeneij F, Macaya C, Rutsch W, et al. (1994) N Engl J Med 331: 489-495.

59. Fischman DL, Leon MB, Baim DS, Schatz RA, Savage MP, et al. (1994) A randomized comparison of coronary-stent placement and balloon angioplasty in the treatment of coronary artery disease. Stent Restenosis Study Investigators. N Engl J Med 331: 496-501.

60. Sutton JM, Ellis SG, Roubin GS, Pinkerton CA, King SB 3rd, et al. (1994) Major clinical events after coronary stenting. The multicenter registry of acute and elective Gianturco-Roubin stent placement. The Gianturco-Roubin Intracoronary Stent Investigator Group. Circulation 89: 1126-1137.

61. George BS, Voorhees WD 3rd, Roubin GS, Fearnot NE, Pinkerton CA, et al. (1993) Multicenter investigation of coronary stenting to treat acute or threatened closure after percutaneous transluminal coronary angioplasty: clinical and angiographic outcomes. J Am Coll Cardiol 22: 135-143. 
62. Favaloro RG (1968) Saphenous vein autograft replacement of severe segmental coronary artery occlusion: operative technique. Ann Thorac Surg 5: 334-339.

63. Buxton BF, Komeda M, Fuller JA, Gordon I (1998) Bilateral internal thoracic artery grafting may improve outcome of coronary artery surgery. Risk-adjusted survival. Circulation 98: ॥1-6.

64. Janssen DP, Noyez L, Wouters C, Brouwer RM (2004) Preoperative prediction of prolonged stay in the intensive care unit for coronary bypass surgery. Eur $\mathrm{J}$ Cardiothorac Surg 25: 203-207.

65. Tavilla G, Kappetein AP, Braun J, Gopie J, Tjien AT, et al. (2004) Long-term follow-up of coronary artery bypass grafting in three-vessel disease using exclusively pedicled bilateral internal thoracic and right gastroepiploic arteries. Ann Thorac Surg 77: 794-799.

66. Barner HB (2008) Operative treatment of coronary atherosclerosis. Ann Thorac Surg 85: 1473-1482.

67. Daemen J, Boersma E, Flather M, Booth J, Stables R, et al. (2008) Long-term safety and efficacy of percutaneous coronary intervention with stenting and coronary artery bypass surgery for multivessel coronary artery disease: a metaanalysis with 5-year patient-level data from the ARTS, ERACI-II, MASS-II, and SoS trials. Circulation 118: 1146-1154.

68. Serruys PW, Morice MC, Kappetein AP, Colombo A, Holmes DR, et al. (2009) Percutaneous coronary intervention versus coronary-artery bypass grafting for severe coronary artery disease. N Engl J Med 360: 961-972.

69. Lange RA, Hillis LD (2009) Coronary revascularization in context. N Engl J Med 360: 1024-1026

70. Al-Nozha MM, Arafah MR, Al-Mazrou YY, Al-Maatouq MA, Khan NB, et al. (2004) Coronary artery disease in Saudi Arabia. Saudi Med J 25: 1165-1171.

71. Al-Nozha MM, Al-Maatouq MA, Al-Mazrou YY, Al-Harthi SS, Arafah MR, et al (2004) Diabetes mellitus in Saudi Arabia. Saudi Med J 25: 1603-1610.

72. Al-Nozha MM, Al-Mazrou YY, Al-Maatouq MA, Arafah MR, Khalil MZ, et al. (2005) Obesity in Saudi Arabia. Saudi Med J 26: 824-829.

73. Al-Nozha M, Al-Khadra A, Arafah MR, Al-Maatouq MA, Khalil MZ, et al. (2005) Metabolic syndrome in Saudi Arabia. Saudi Med J 26: 1918-1925.

74. Al-Nozha MM, Abdullah M, Arafah MR, Khalil MZ, Khan NB, et al. (2007) Hypertension in Saudi Arabia. Saudi Med J 28: 77-84.

75. Al-Nozha MM, Arafah MR, Al-Maatouq MA, Khalil MZ, Khan NB, et al. (2008) Hyperlipidemia in Saudi Arabia. Saudi Med J 29: 282-287.

76. Hu FB, Willett WC (2002) Optimal diets for prevention of coronary heart disease. JAMA 288: 2569-2578.

77. Mente A, de Koning L, Shannon HS, Anand SS (2009) A systematic review of the evidence supporting a causal link between dietary factors and coronary heart disease. Arch Intern Med 169: 659-669.

78. Mozaffarian D, Clarke R (2009) Quantitative effects on cardiovascular risk factors and coronary heart disease risk of replacing partially hydrogenated vegetable oils with other fats and oils. Eur J Clin Nutr 2: S22-S33.

79. Lavie CJ, Thomas RJ, Squires RW, Allison TG, Milani RV (2009) Exercise training and cardiac rehabilitation in primary and secondary prevention of coronary heart disease. Mayo Clin Proc 84: 373-383.

80. Leon AS, Franklin BA, Costa F, Balady GJ, Berra KA, et al. (2005) Cardiac rehabilitation and secondary prevention of coronary heart disease: an American Heart Association scientific statement from the Council on Clinical Cardiology (Subcommittee on Exercise, Cardiac Rehabilitation, and Prevention) and the Council on Nutrition, Physical Activity, and Metabolism (Subcommittee on Physical Activity), in collaboration with the American association of Cardiovascular and Pulmonary Rehabilitation. Circulation 111: 369-376.

81. Eisenmann JC (2004) Physical activity and cardiovascular disease risk factors in children and adolescents: an overview. Can J Cardiol 20: 295-301.

82. Eisenmann JC, Welk GJ, Wickel EE, Blair SN (2007) Combined influence of cardiorespiratory fitness and body mass index on cardiovascular disease risk factors among 8-18 year old youth: The Aerobics Center Longitudinal Study. Int J Pediatr Obes 2: 66-72.

83. Eisenmann JC, Welk GJ, Ihmels M, Dollman J (2007) Fatness, fitness, and cardiovascular disease risk factors in children and adolescents. Med Sci Sports Exerc 39: 1251-1256.

84. Jekal Y, Kim ES, Im JA, Park JH, Lee MK, et al. (2009) Interaction between fatness and fitness on CVD risk factors in Asian youth. Int J Sports Med 30: 733-740.
85. Carnethon MR, Gulati M, Greenland P (2005) Prevalence and cardiovascula disease correlates of low cardiorespiratory fitness in adolescents and adults. JAMA 294: 2981-2988.

86. Ribeiro JC, Guerra S, Oliveira J, Andersen LB, Duarte JA, et al. (2004) Body fatness and clustering of cardiovascular disease risk factors in Portuguese children and adolescents. Am J Hum Biol 16: 556-562.

87. Behan MW, Chew DP, Aylward PE (2010) The role of antiplatelet therapy in the secondary prevention of coronary artery disease. Curr Opin Cardiol 25: 321-328.

88. Allen JK, Dennison CR (2010) Randomized trials of nursing interventions for secondary prevention in patients with coronary artery disease and heart failure: systematic review. J Cardiovasc Nurs 25: 207-220.

89. Delles C, Dymott JA, Neisius U, Rocchiccioli JP, Bryce GJ, et al. (2010) Reduced LDL-cholesterol levels in patients with coronary artery disease are paralleled by improved endothelial function: An observational study in patients from 2003 and 2007. Atherosclerosis 211: 271-277.

90. Hall SL, Lorenc T (2010) Secondary prevention of coronary artery disease. Am Fam Physician 81: 289-296.

91. Pajak A, Jankowski $P$, Kawecka-Jaszcz K, Surowiec $S$, Wolfshaut $R$, et al. (2009) Changes in secondary prevention of coronary artery disease in the post-discharge period over the decade 1997-2007. Results of the Cracovian Program for Secondary Prevention of Ischaemic Heart Disease and Polish parts of the EUROASPIRE II and III surveys. Kardiol Pol 67: 1353-1359.

92. Piepoli MF, Corrá U, Benzer W, Bjarnason-Wehrens B, Dendale $\mathrm{P}$, et al. (2010) Secondary prevention through cardiac rehabilitation: from knowledge to implementation. A position paper from the Cardiac Rehabilitation Section of the European Association of Cardiovascular Prevention and Rehabilitation. Eur J Cardiovasc Prev Rehabil 17: 1-17.

93. Furukawa Y, Taniguchi R, Ehara N, Ozasa N, Haruna Y, et al. (2008) Bette survival with statin administration after revascularization therapy in Japanese patients with coronary artery disease: perspectives from the CREDO-Kyoto registry. Circ J 72: 1937-1945.

94. Karastergiou K, Kaski JC (2008) Medical management of the diabetic patient with coronary artery disease. Curr Pharm Des 14: 2527-2536.

95. Goldenberg I, Benderly M, Sidi R, Boyko V, Tenenbaum A, et al. (2009) Relation of clinical benefit of raising high-density lipoprotein cholesterol to serum levels of low-density lipoprotein cholesterol in patients with coronary heart disease (from the Bezafibrate Infarction Prevention Trial). Am J Cardiol 103: 41-45

96. Mehta RH, Bhatt DL, Steg PG, Goto S, Hirsch AT, et al. (2008) Modifiable risk factors control and its relationship with 1 year outcomes after coronary artery bypass surgery: insights from the REACH registry. Eur Heart J 29: 3052-3060.

97. Jankowski P, Kawecka-Jaszcz K, Pajak A, Surowiec S, Wolfshaut R, et al (2009) Secondary prevention of coronary artery disease in hospital practice over the decade 1996-2006. Results of the Cracovian Program for Secondary Prevention of Ischaemic Heart Disease and Polish parts of the EUROASPIRE II and EUROASPIRE III surveys. Kardiol Pol 67: 970-977.

98. Wannamethee SG, Shaper AG (2001) Physical activity in the prevention of cardiovascular disease: an epidemiological perspective. Sports Med 31: 101114.

99. Davies MJ (1996) Stability and instability: two faces of coronary atherosclerosis The Paul Dudley White Lecture 1995. Circulation 94: 2013-2020. 